\title{
Case Report \\ Clear Cell Carcinoma Arising from Cesarean Section Scar Endometriosis: Case Report and Review of the Literature
}

\author{
Sakura Ijichi, Taisuke Mori, Izumi Suganuma, Takuro Yamamoto, Hiroshi Matsushima, \\ Fumitake Ito, Makoto Akiyama, Izumi Kusuki, and Jo Kitawaki
}

Department of Obstetrics and Gynecology, Graduate School of Medical Science, Kyoto Prefectural University of Medicine, 465 Kajii-cho, Kawaramachi-Hirokoji, Kamigyo-ku, Kyoto 602-8566, Japan

Correspondence should be addressed to Taisuke Mori; moriman@koto.kpu-m.ac.jp

Received 9 August 2014; Accepted 8 October 2014; Published 2 November 2014

Academic Editor: Seung-Yup Ku

Copyright (C) 2014 Sakura Ijichi et al. This is an open access article distributed under the Creative Commons Attribution License, which permits unrestricted use, distribution, and reproduction in any medium, provided the original work is properly cited.

Introduction. The incidence of endometriosis affecting skin tissue represents only $0.5-1.0 \%$ of all endometriosis cases. A malignancy in the abdominal wall arising from endometriosis following cesarean section is even rarer; only 21 cases have previously been reported. The therapeutic strategy has not been determined because of the limited cases. We report a case of clear cell adenocarcinoma arising in the abdominal wall from endometriosis tissues following cesarean section and review previous literature to achieve the optimal treatment and better prognosis. Case Presentation. A 60-year-old woman presented with a growing mass at the left side of a cesarean section scar. Radical resection of the abdominal wall mass was performed. Histopathological examination showed a clear cell adenocarcinoma. Benign endometrium-like tissues were found adjacent to the cancer lesion in the excised specimen, suggesting malignant transformation from endometriosis of the abdominal wall. Discussion. Local resection was performed in 10 cases $(47.6 \%)$ and total abdominal hysterectomy or oophorectomy was conducted in 11 cases (52.4\%). No malignant lesions were observed in either the uterus or adnexa that were resected. These cases may be expected to increase with increasing incidence of cesarean section. The significance of the extensional resection should be further elucidated.

\section{Introduction}

Endometriosis is a common disease that occurs in 5$10 \%$ of women of reproductive age, typically affecting the pelvic organs. Extrapelvic endometriosis is an uncommon event, known as "deep infiltrating endometriosis (DIE)." Endometriosis in the abdominal wall involves scar tissue resulting from gynecological procedures [1]. Overall, malignant transformation of DIE of any type is rare. Here, we report a case of clear cell carcinoma arising in the abdominal wall from endometriosis tissue following cesarean section.

\section{Case Presentation}

A 60 -year-old woman, gravida 3 para 2, presented with a growing mass at the left side of a cesarean section scar (lower abdominal longitudinal incision). She had no relevant medical history and had undergone cesarean section twice, the first in 1977 due to breech presentation and again in 1979.
She had no pertinent family history other than breast cancer diagnosed in her sister and had experienced menopause at 50 years of age.

The patient noticed the nodule near the abdominal operation scar with no tenderness 4 years before presentation. The nodule grew quickly in size with no significant pain, even during menstruation. Physical examination revealed a smooth mass measuring $4 \mathrm{~cm}$ in diameter on the middleleft side of the cesarean median scar (Figure 1(a)). A biopsy of the mass showed atypical cells, and subsequent pelvic magnetic resonance imaging (MRI) showed two lesions, measuring $2.5 \times 3.3 \mathrm{~cm}$ and $3.3 \times 4.0 \mathrm{~cm}$ along the abdominal scar (Figure 2(b)). The mass located at the right side of the scar consisted of solid components, while that on the left was polycystic. There were no obvious mass-like lesions in the intraperitoneal cavity or any of the abdominal or pelvic lymph nodes. Laboratory tests revealed no increase in the serum levels of tumor markers (CEA, CA19-9, and CA125). Radical resection of the abdominal wall mass was 


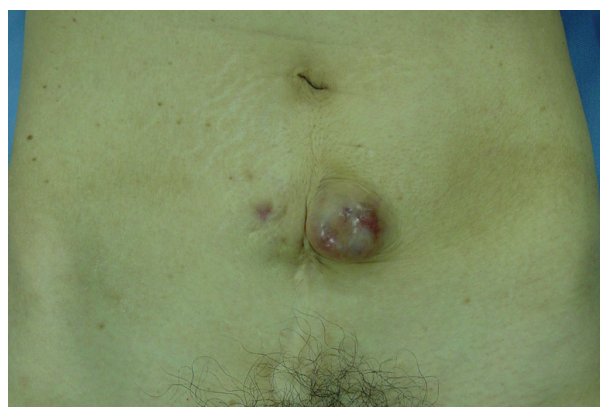

(a)

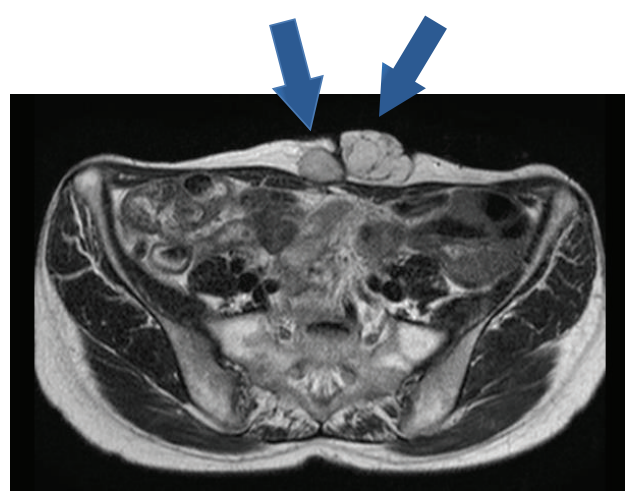

(b)

FIgURE 1: (a) Smooth mass on the middle-left side of the cesarean median scar. (b) Pelvic MRI (T2 weighted image, axial section). MRI shows the tumor associated with cesarean section scar. The right side of the scar consists of solid components and the tumor at the left side of the scar is polycystic.

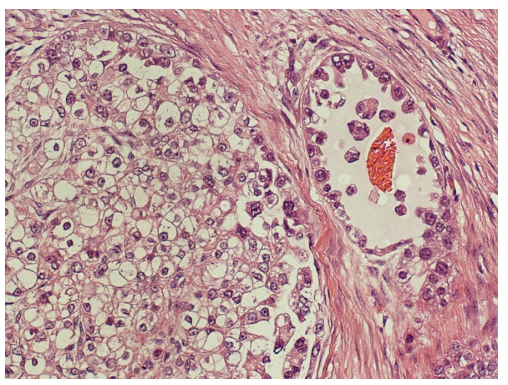

(a)

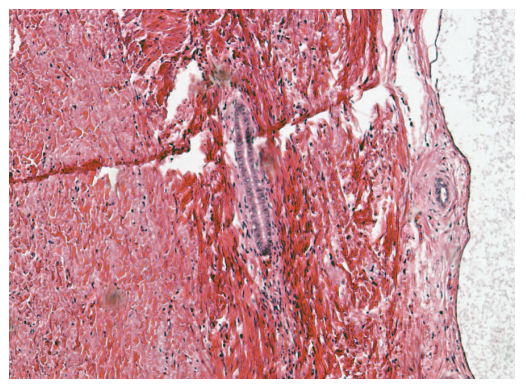

(b)

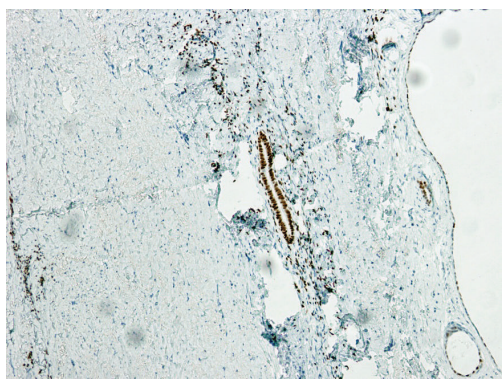

(c)

FIGURE 2: (a) In pathologic examination, many hobnail-shaped cells and clear cell were found. These are characteristic of clear cell adenocarcinoma (hematoxylin and eosin stain, magnification $\times 100$ ). (b) Pathologic examination showed clear cell adenocarcinoma and endometriosis. It suggests a malignant transformation from endometriosis of the abdominal wall (hematoxylin and eosin stain, magnification $\times 100$ ). (c) Staining estrogen receptor (ER), magnification $\times 100$.

performed with adequate margins under general anesthesia. Histopathological examination showed clear cell adenocarcinoma (Figure 2(a)), suggesting malignant transformation from endometriosis of the abdominal wall. Positron emission tomography (PET) showed no evidence of malignancy, including in the uterus, bilateral ovaries, and pelvic lymph nodes. Considering these findings together, we diagnosed clear cell adenocarcinoma of the abdominal wall arising from endometriosis after cesarean section. Eight months after the resection, a nodular lesion appeared in the patient's abdominal scar again. MRI and PET scan showed local recurrence, and she was hospitalized for resection of the recurring tumor and abdominal wall reconstruction. Histopathological examination showed the lesion to be clear cell adenocarcinoma. At 15 months after the second operation, there was no further evidence of the disease on imaging studies or clinical examination.

\section{Discussion}

Endometriosis in the extrapelvic organs is rather rare. Moreover, endometriosis affecting skin tissue is even rarer; its incidence represents only $0.5-1.0 \%$ of all endometriosis cases, being typically found at the site of surgical scars. In this case, we discovered a malignancy in the abdominal wall arising from endometriosis following cesarean section. Previous reports concerning malignant transformation of abdominal wall endometriosis are very few (only 21 cases found in a literature review; we used the following keywords: clear cell adenocarcinoma, endometriosis, and malignant transformation); the details from these reports are shown in Table 1. Among these, in 19 cases (90.5\%), malignancy occurred at the site of the cesarean section scar. The remaining two cases resulted from a scar of gynecological surgery involving myomectomy and hysterectomy, suggesting that the interfusion of endometrium into the abdominal wall at the time of surgery may contribute to carcinogenesis.

The interfusion of endometrium into the abdominal wall affects $1 \%$ of women undergoing intrapelvic surgery [2], indicating that scar endometriosis is caused by iatrogenic factors [3]. Malignant transformation of endometriosis occurs in $0.75 \%$ of women who suffer from endometriosis, and in nearly $20 \%$ of cases, it occurs at extraovarian sites [4]. As shown in Table 1, the histological characteristics of malignant transformation in endometriosis of the abdominal wall are primarily represented by clear cell carcinoma (15/21; 71.4\%), 
TABLE 1: Twenty-one cases of malignant transformation from abdominal wall endometriosis.

\begin{tabular}{|c|c|c|c|c|c|c|c|c|c|c|c|}
\hline No. & Reference & $\begin{array}{c}\text { Age } \\
\text { (years) }\end{array}$ & $\begin{array}{l}\text { Previous } \\
\text { surgery }\end{array}$ & $\begin{array}{l}\text { Delay } \\
\text { (years) }\end{array}$ & Histology & $\begin{array}{l}\text { Coexisting } \\
\text { endometrio- } \\
\text { sis on } \\
\text { histology }\end{array}$ & $\begin{array}{l}\text { Surgical } \\
\text { treatment }\end{array}$ & CT & RT & $\begin{array}{l}\text { Followup } \\
\text { (months) }\end{array}$ & Outcome \\
\hline 1. & $\begin{array}{c}\text { Schnieber and } \\
\text { Wagner-Kolb } \\
{[8]}\end{array}$ & 40 & CS & 15 & $\mathrm{CCC}$ & Yes & $\begin{array}{l}\text { LR, TAH + } \\
\quad \text { BSO }\end{array}$ & - & + & 18 & DOD \\
\hline 2. & Hitti et al. [9] & 46 & CS & 14 & CCC & Yes & $\begin{array}{c}\mathrm{LR}, \mathrm{TAH}+ \\
\mathrm{BSO}\end{array}$ & - & - & 30 & NED \\
\hline 3. & $\begin{array}{l}\text { Markopoulos et } \\
\text { al. [10] }\end{array}$ & 50 & CS & 25 & $\mathrm{EC}$ & No & LR & - & - & 24 & NED \\
\hline 4. & Gücer et al. [11] & 45 & CS & 8 & $\mathrm{EC}$ & Unclear & LR & - & - & 20 & DOD \\
\hline 5. & Miller et al. [12] & 38 & CS & 9 & $\mathrm{CCC}$ & Yes & $\begin{array}{c}\text { LR, TAH + } \\
\text { BSO }\end{array}$ & - & + & 60 & NED \\
\hline 6. & Park et al. [13] & 54 & CS & 26 & CCC & Yes & LR & - & + & 6 weeks & NED \\
\hline 7. & Ishida et al. [14] & 56 & CS & 24 & $\mathrm{CCC}$ & No & LR & - & + & 48 & DOD \\
\hline 8. & Matter et al. [15] & 60 & CS & 41 & $\mathrm{EC}$ & Yes & LR & - & - & 18 & NED \\
\hline 9. & Li et al. [16] & 38 & CS & 10 & SC & No & $\begin{array}{c}\mathrm{LR}, \mathrm{TAH}+ \\
\mathrm{BSO}+\mathrm{OMT}\end{array}$ & - & - & 14 & NED \\
\hline 10. & Leng et al. [17] & 41 & CS & 16 & Carcinosarcoma & Yes & LR & - & - & 15 & DOD \\
\hline 11. & $\begin{array}{l}\text { Sergent et al. } \\
{[18]}\end{array}$ & 45 & CS & 28 & CCC & No & LR, BSO & + & - & 6 & DOD \\
\hline 12. & Harry et al. [19] & 55 & CS & 30 & CCC & Yes & LR & - & + & 18 & NED \\
\hline 13. & Bats et al. [20] & 38 & CS & 13 & $\mathrm{CCC}$ & Yes & $\begin{array}{c}\text { LR, TAH + } \\
\text { BSO }\end{array}$ & + & - & 2 & NED \\
\hline 14. & $\begin{array}{l}\text { Williams et al. } \\
\qquad 21]\end{array}$ & 53 & CS & 17 & $\mathrm{CCC}$ & No & $\begin{array}{c}\mathrm{LR}, \mathrm{TAH}+ \\
\mathrm{BSO}\end{array}$ & + & + & 11 & DOD \\
\hline 15. & $\begin{array}{c}\text { Matsuo et al. } \\
{[22]}\end{array}$ & 37 & $\mathrm{LC}$ & 10 & $\mathrm{CCC}$ & No & $\begin{array}{c}\mathrm{LR}, \mathrm{TAH}+ \\
\mathrm{BSO}+\mathrm{OMT}, \\
\text { PEN }\end{array}$ & + & - & 18 & REC \\
\hline 16. & $\begin{array}{l}\text { Omranipour } \\
\text { and Najafi [23] }\end{array}$ & 59 & $\mathrm{D} \& \mathrm{C}^{*}$ & 20 & SC & No & LR & + & - & 12 & NED \\
\hline 17. & $\begin{array}{c}\text { Bourdel et al. } \\
\text { [24] }\end{array}$ & 43 & CS & Unclear & CCC & Unclear & $\begin{array}{c}\text { LR, TAH + } \\
\text { BSO }\end{array}$ & + & + & 22 & DOD \\
\hline 18. & Shalin et al. [7] & 47 & CS & Unclear & $\mathrm{CCC}$ & Yes & LR & + & + & 7 & NED \\
\hline 19. & Mert et al. [25] & 42 & CS, USO & Unclear & CCC & Yes & $\begin{array}{l}\mathrm{LR}, \mathrm{TAH}+ \\
\quad \mathrm{BSO}\end{array}$ & + & - & 1 & NED \\
\hline 20. & Mert et al. [25] & 51 & $\mathrm{CS}, \mathrm{TAH}$ & Unclear & $\mathrm{CCC}$ & Yes & $\begin{array}{l}\mathrm{LR}, \mathrm{BSO}+ \\
\quad \mathrm{OMT}\end{array}$ & - & + & 31 & NED \\
\hline 21. & This case & 60 & CS & 35 & $\mathrm{CCC}$ & Yes & LR & - & - & 8 & REC \\
\hline
\end{tabular}

BSO: bilateral salpingo-oophorectomy, CCC: clear cell adenocarcinoma, CS: cesarean section, D \& C: dilatation and curettage, DOD: died of disease, EC: endometrioid adenocarcinoma, LC: laparoscopic cystectomy, LR: local resection, NED: no evidence of disease, OMT: omentectomy, PEN: pelvic lymph nodes dissection, REC: recurrence, SC: serous adenocarcinoma, TAH: total abdominal hysterectomy, USO: unilateral salpingo-oophorectomy, and * laparotomy for perforation of the uterus during D \& C.

followed by endometrioid adenocarcinoma (3/21; $14.3 \%)$, serous adenocarcinoma $(2 / 21 ; 9.5 \%)$, and carcinosarcoma $(1 / 21 ; 4.8 \%)$.

In 1925, Sampson [5] proposed the criteria for the diagnosis of malignancy arising in endometriosis as follows: (1) demonstration of both benign and neoplastic endometrial tissues in the tumor, (2) the histology being compatible with endometrial origin, and (3) no other primary tumor sites being found. Further, in 1953, Scott [6] postulated a fourth criterion; that is, (4) the morphologic demonstration of benign endometriosis contiguous with the malignant tissue is a prerequisite for adjudication of a malignancy originating in endometriosis. In the present case, the first three criteria were fulfilled. Considering the fourth criterion in our patient, benign endometrium-like tissues were found adjacent to the clear cell carcinoma lesion (Figures 2(b) and 2(c)), suggesting that the majority of the endometriosis tissue in the abdominal wall had been replaced by cancer tissue.

Clear cell carcinoma is known as a representative histological type in renal cell cancer, pancreatic cancer, adrenal 
cancer, and gynecological cancer [7]. Immunohistochemical analysis has shown that tumor cells in gynecological cancer tissues stain positive for CK7 and negative for CK20 [7], while glypican-3 is generally positive in hepatocellular cancer and renal cell cancer. In this case, immunohistochemistry was positive/negative for CK7/CK20 and negative for glypican3 , suggesting that this tumor could be metastatic tissue from gynecological cancer. Based on this evidence, we diagnosed this tumor as malignant transformation from abdominal wall endometriosis after cesarean section.

In all the 21 cases found in the literature, surgical treatment was performed for malignant transformation of abdominal wall endometriosis. Among these, local resection was performed in 10 cases $(47.6 \%)$, and total abdominal hysterectomy or salpingo-oophorectomy was conducted in 11 cases (52.4\%). However, no malignant lesions were observed in either the uterus or both the adnexa that were resected, suggesting that the significance of the extensional resection, including hysterectomy or oophorectomy, remains unclear. For our patient, we chose only local resection of the lesion since PET-CT did not show the presence of any malignant lesions. However, the patient experienced a relapse lesion in the same area of the cesarean section scar at 8 months after the first surgery. Previous reports showed that 9 patients (42.9\%) underwent relapse and 7 patients (33.3\%) died of this disease. Once recurrence occurred, no treatment-including chemotherapy and radiation therapy-was effective. Most cases shown in Table 1 occurred subsequent to cesarean section. With the increasing incidence of cesarean sections, the number of cases with similar malignant transformation of abdominal wall endometriosis may be expected to increase. Further studies are necessary to determine the optimal treatment for malignant transformation of abdominal wall endometriosis.

\section{Conflict of Interests}

The authors declare that there is no conflict of interests regarding the publication of this paper.

\section{References}

[1] C. C. Liang, B. Liou, C. C. Tsai, T. C. Chen, and Y. K. Soong, "Scar Endometriosis," International Surgery, vol. 83, no. 1, pp. 69-71, 1998.

[2] R. Victory, M. P. Diamond, and D. A. Johns, "Villar's nodule: a case report and systematic literature review of endometriosis externa of the umbilicus," Journal of Minimally Invasive Gynecology, vol. 14, no. 1, pp. 23-32, 2007.

[3] J. Greenhill, "Scar endometriosis," The American Journal of Obstetrics and Gynecology, vol. 44, no. 1, p. 177, 1942.

[4] L. Benoit, L. Arnould, N. Cheynel et al., "Malignant extraovarian endometriosis: a review," European Journal of Surgical Oncology, vol. 32, no. 1, pp. 6-11, 2006.

[5] J. A. Sampson, "Endometrial carcinoma of the ovary arising in endometrial tissue in that organ," The American Journal of Obstetrics and Gynecology, vol. 9, no. 1, pp. 111-114, 1925.

[6] R. B. Scott, "Malignant changes in endometriosis," Obstetrics and Gynecology, vol. 2, no. 3, pp. 283-289, 1953.
[7] S. C. Shalin, A. L. Haws, D. G. Carter, and N. Zarrin-Khameh, "Clear cell adenocarcinoma arising from endometriosis in abdominal wall cesarean section scar: a case report and review of the literature," Journal of Cutaneous Pathology, vol. 39, no. 11, pp. 1035-1041, 2012.

[8] D. Schnieber and D. Wagner-Kolb, "Malignant degeneration of an extragenital endometriosis," Geburtshilfe und Frauenheilkunde, vol. 46, no. 9, pp. 658-659, 1986.

[9] I. F. Hitti, S. S. Glasberg, and S. Lubicz, "Clear cell carcinoma arising in extraovarian endometriosis: report of three cases and review of the literature," Gynecologic Oncology, vol. 39, no. 3, pp. 314-320, 1990.

[10] C. Markopoulos, H. Gogas, G. Eleftheriou, and D. Floros, "Endometrioid carcinoma arising in a scar of caesarean section. Case report," European Journal of Gynaecological Oncology, vol. 17, no. 6, pp. 520-521, 1996.

[11] F. Gücer, O. Reich, R. Kömetter, and D. Pieber, "Endometroid carcinoma arising within a scar endometriosis," European Journal of Gynaecological Oncology, vol. 18, no. 1, pp. 42-43, 1997.

[12] D. M. Miller, J. J. Schouls, and T. G. Ehlen, "Clear cell carcinoma arising in extragonadal endometriosis in a caesarean section scar during pregnancy," Gynecologic Oncology, vol. 70, no. 1, pp. 127-130, 1998.

[13] S. W. Park, S. M. Hong, H. G. Wu, and S. W. Ha, "Clear cell carcinoma arising in a cesarean section scar endometriosis: a case report," Journal of Korean Medical Science, vol. 14, no. 2, pp. 217-219, 1999.

[14] G. M. Ishida, T. Motoyama, T. Watanabe, and I. Emura, "Clear cell carcinoma arising in a cesarean section scar. Report of a case with fine needle aspiration cytology," Acta Cytologica, vol. 47, no. 6, pp. 1095-1098, 2003.

[15] M. Matter, N. Schneider, and T. McKee, "Cystadenocarcinoma of the abdominal wall following caesarean section: case report and review of the literature," Gynecologic Oncology, vol. 91, no. 2, pp. 438-443, 2003.

[16] J.-Y. Li, Y.-J. Chen, Y.-C. Wu et al., “Two- and three-dimensional Doppler ultrasound analysis of abdominal wall clear cell carcinoma," Ultrasound in Obstetrics and Gynecology, vol. 22, no. 1, pp. 98-100, 2003.

[17] J. Leng, J. Lang, L. Guo, H. Li, and Z. Liu, "Carcinosarcoma arising from atypical endometriosis in a cesarean section scar," International Journal of Gynecological Cancer, vol. 16, no. 1, pp. 432-435, 2006.

[18] F. Sergent, M. Baron, J.-B. le Cornec, M. Scotté, P. Mace, and L. Marpeau, "Malignant transformation of abdominal wall endometriosis: a new case report," Journal de Gynecologie Obstetrique et Biologie de la Reproduction, vol. 35, no. 2, pp. 186190, 2006.

[19] V. N. Harry, S. Shanbhag, M. Lyall, G. V. Narayansingh, and D. E. Parkin, "Isolated clear cell adenocarcinoma in scar endometriosis mimicking an incisional hernia," Obstetrics and Gynecology, vol. 110, no. 2, pp. 469-471, 2007.

[20] A. S. Bats, Y. Zafrani, P. Pautier, P. Duvillard, and P. Morice, "Malignant transformation of abdominal wall endometriosis to clear cell carcinoma: case report and review of the literature," Fertility and Sterility, vol. 90, no. 4, pp. 1197.e13-1197.e16, 2008.

[21] C. Williams, P. Petignat, A. Belisle, and P. Drouin, "Primary abdominal wall clear cell carcinoma: case report and review of literature," Anticancer Research, vol. 29, no. 5, pp. 1591-1593, 2009.

[22] K. Matsuo, E. L. C. Alonsozana, M. L. Eno et al., "Primary peritoneal clear cell adenocarcinoma arising in previous abdominal 
scar for endometriosis surgery," Archives of Gynecology and Obstetrics, vol. 280, no. 4, pp. 637-641, 2009.

[23] R. Omranipour and M. Najafi, "Papillary serous carcinoma arising in abdominal wall endometriosis treated with neoadjuvant chemotherapy and surgery," Fertility and Sterility, vol. 93, no. 4, pp. e1347-e1348, 2010.

[24] N. Bourdel, M. Durand, P. Gimbergues, J. Dauplat, and M. Canis, "Exclusive nodal recurrence after treatment of degenerated parietal endometriosis," Fertility and Sterility, vol. 93, no. 6, pp. 2074.el-2074.e6, 2010.

[25] I. Mert, A. Semaan, S. Kim, R. Ali-Fehmi, and R. T. Morris, "Clear cell carcinoma arising in the abdominal wall: two case reports and literature review," American Journal of Obstetrics and Gynecology, vol. 207, no. 2, pp. e7-e9, 2012. 


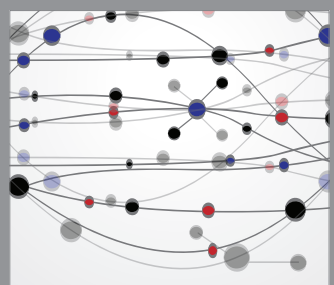

The Scientific World Journal
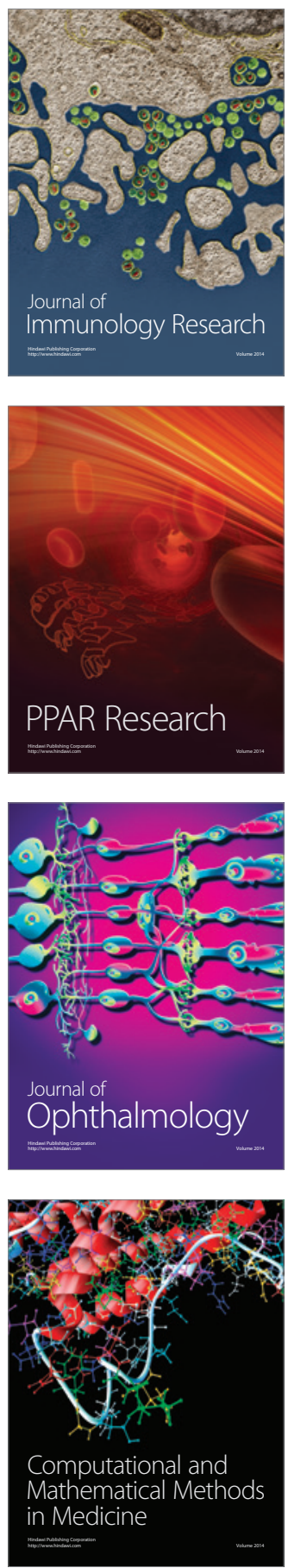

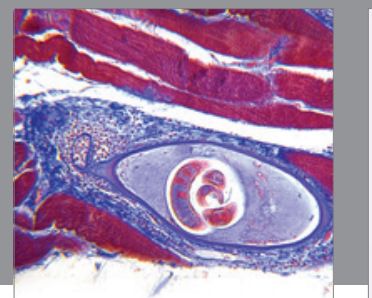

Gastroenterology

Research and Practice
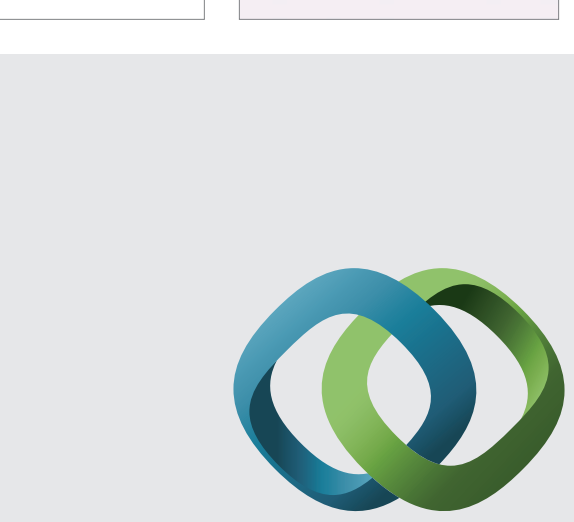

\section{Hindawi}

Submit your manuscripts at

http://www.hindawi.com
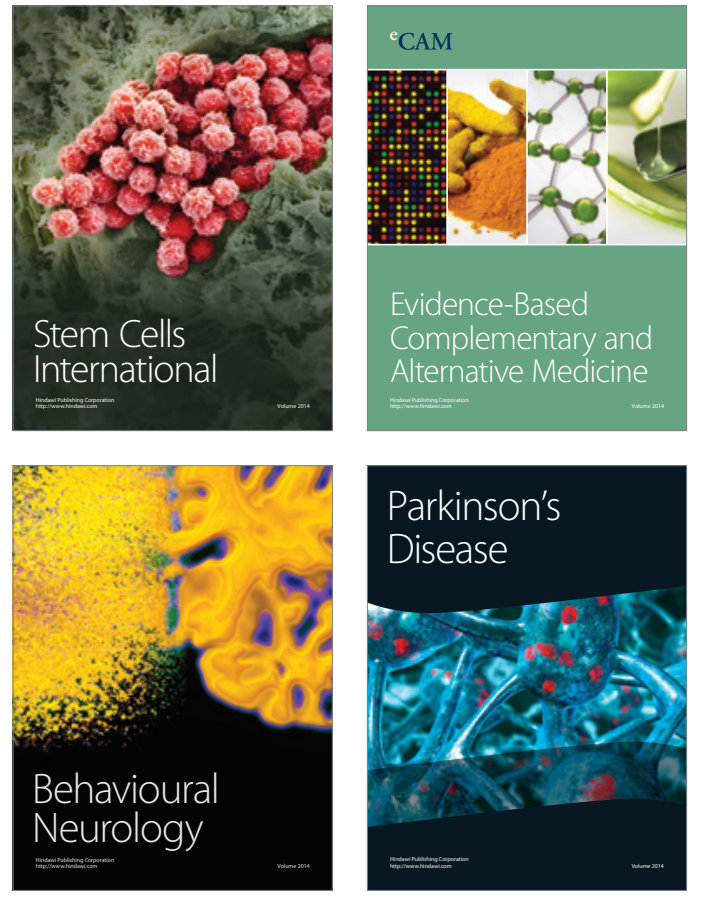
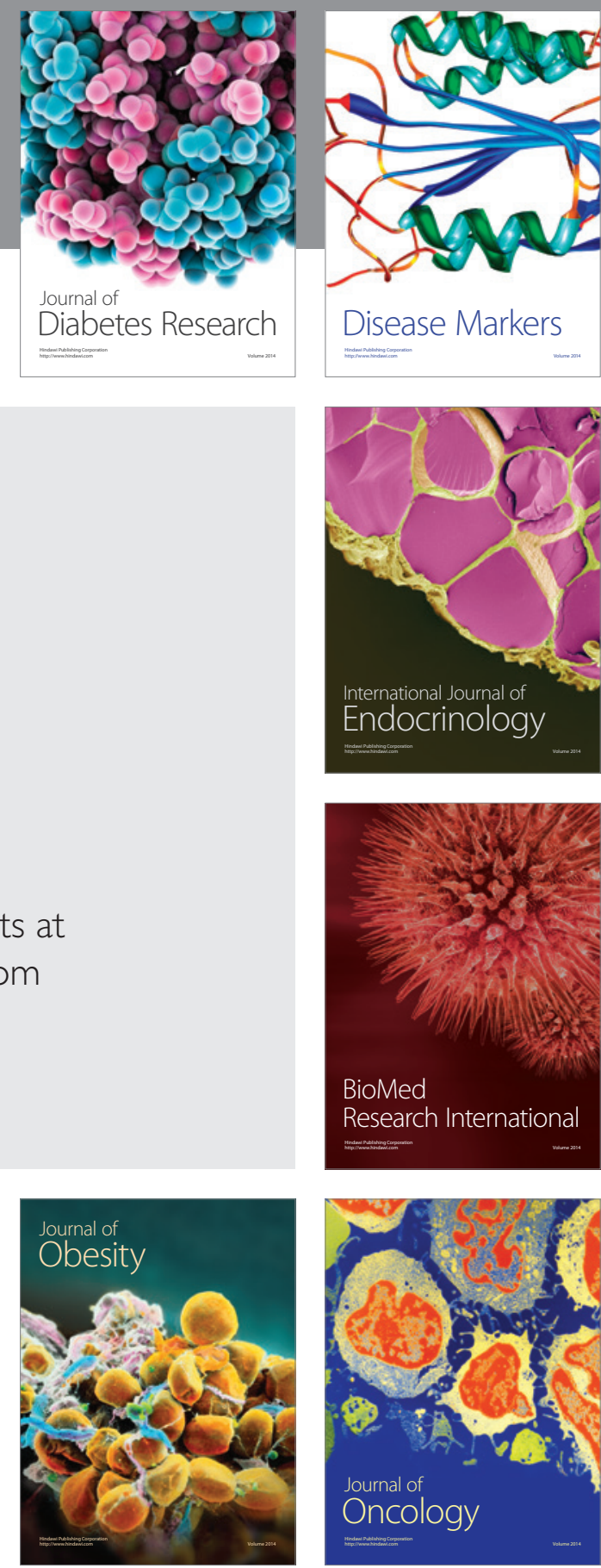

Disease Markers
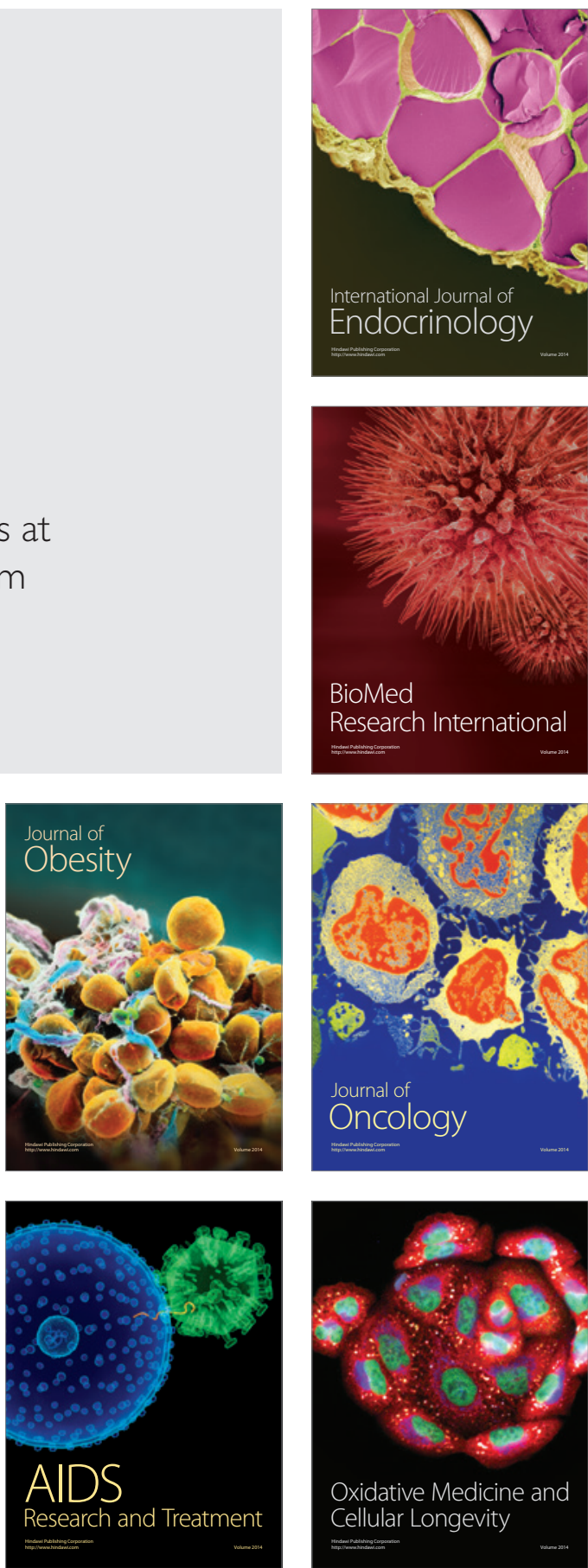